\title{
The Effect of Photobiomodulation on Distraction Osteogenesis
}

\author{
Sarvin Sarmadi ${ }^{1}$, Behrad Tanbakuchi ${ }^{1 *}$, Arian Hesam Arefi' ${ }^{2}$, Nasim Chiniforush ${ }^{3}$ \\ 'Department of Orthodontics, School of Dentistry, Tehran University of Medical Sciences, Tehran, Iran \\ ${ }^{2}$ Orthodontist \\ ${ }^{3}$ Laser Research Center of Dentistry (LRCD), Dentistry Research Institute, Tehran University of Medical Sciences, Tehran, \\ Iran
}

\author{
*Correspondence to \\ Behrad Tanbakuchi, Assistant \\ Professor, Department of \\ Orthodontics, School of Dentistry, \\ Tehran University of Medical \\ Sciences, Tehran, Iran. \\ Email: \\ behrad.tanbakuchi@yahoo.com
}

Published online October 1, 2019

\begin{abstract}
Distraction osteogenesis (DO) is a surgical procedure to increase bone height in different body parts. DO includes a surgical incision, wherein the bone is cut and a device is installed for further separation of the two ends by gradual unscrewing of the device screw. New bone gradually forms and fills the gap, and the bone height increases as such.

Photobiomodulation (PBM) or low-level laser therapy (LLLT) enhances the formation of soft and hard tissue such as bone and can, therefore, accelerate the process of DO and shorten the duration of different surgical phases of DO such as latency, activation, and consolidation.

Different laser types with variable exposure settings and protocols have been used for this purpose. The gallium-aluminum-arsenide (GaAlAs) diode laser is the most commonly used laser type for LLLT. This study reviews 18 published articles on the effects of LLLT on DO and summarizes their findings to further elucidate this topic.

Keywords: Photobiomodulation; Low-Level Laser Therapy; Distraction Osteogenesis; Bone Healing; Surgically-Assisted Rapid Palatal Expansion.
\end{abstract}

\section{Introduction}

Photobiomodulation (PBM) or low-level laser therapy (LLLT) is a none-invasive modality extensively used in medicine and contemporary dentistry. ${ }^{1}$ It uses a low-level laser (LLL) with a wavelength of 632 to $1064 \mathrm{~nm}$ (red and infrared spectra) to stimulate a biological response. ${ }^{1} \mathrm{PBM}$ increases angiogenesis and cell proliferation by providing adenosine triphosphate. ${ }^{2-4}$ The evaluation of the effect of biomodulation by the gallium-aluminum-arsenide (GaAlAs) diode laser on osteoblastic cells reveals that $\mathrm{PBM}$ can change the mitochondrial activity of osteoblasts and osteoblastic cell populations in cell culture media. ${ }^{5}$

The effect of PBM on osteoclast genesis and especially on the expression of receptor activator of nuclear factor kappa-B (RANK), receptor activator of nuclear factor kappa-B ligand (RANKL) and osteoprotegerin (OPG) during orthodontic tooth movement has been previously studied. ${ }^{6}$ RANKL is a cytokine that belongs to the family of tumor necrosis factors and is essential for the induction of osteoclastogenesis. RANKL bonds to the specific RANK receptor on the surface of osteoclast progenitor cells. On the other hand, OPG inhibits osteoclastogenesis by impairing the bonding of RANK to RANKL. A previous study indicated that the enhancement of orthodontic tooth movement by LLL might be due to the expression of RANK/RANKL while OPG-positive cells were not significantly different between the two groups of laser therapy and no laser irradiation. ${ }^{6}$

It has been shown that PBM accelerates the healing time following oral and maxillofacial surgeries, although the evidence in this respect is still inconclusive. ${ }^{7}$ It has been shown that PBM with the GaAlAs laser in a rat model of femur fracture can enhance bone formation in the primary phases of healing. ${ }^{8}$ PBM can decrease pain due to temporomandibular joint disorders and help in relieving orofacial pain. ${ }^{9,10}$

PBM has many applications in dentistry, particularly in endodontics, oral and maxillofacial surgeries such as mandibular distraction, oral pathology, and minor intraoral surgeries to accelerate the fixation of miniscrews, in tooth movement enhancement, and in dental prosthesis. $^{11}$

PBM enhances the tissue response, shortens the primary inflammatory response and accelerates the formation of the new bony matrix in bone healing and bone regeneration around dental implants. It enables the formation of a functional bond between the implant and the bone within 8 weeks. ${ }^{12,13}$

Please cite this article as follows: Sarmadi S, Tanbakuchi B, Hesam Arefi A, Chiniforush N. The effect of photobiomodulation on distraction osteogenesis. J Lasers Med Sci. 2019;10(4):330-337. doi:10.15171/jlms.2019.53. 
PBM increases the rate of angiogenesis in rats by 3.1 folds. It also enhances the healing of oral ulcers, accelerates the proliferation of fibroblasts and increases the amount of elastic and collagen fibers above their normal threshold in primary stages of wound healing. ${ }^{14-17} \mathrm{PBM}$ also affects the mitochondria, release of nitric oxide, reactive oxygen species and gene transcription and expression. ${ }^{18}$

In orthodontics, it has been demonstrated that PBM is effective for biomodulation. It also has analgesic effects and stimulates tissue healing. ${ }^{19,20}$ Such stimulatory effects are due to the ability of LLL to enhance metabolic changes. ${ }^{21} \mathrm{PBM}$ is a non-invasive painless modality with no systemic effect. It is easy to perform and does not require expensive equipment. ${ }^{22}$ Moreover, a study showed that laser irradiation in a pulse mode had a stimulatory effect on bone formation and cell proliferation, especially osteoblasts in primary phases and cell differentiation. ${ }^{23}$

Ilizarov, a Russian physician, was the first person who introduced distraction osteogenesis (DO) in 1951. ${ }^{24}$ DO refers to bone formation between bony surfaces by gradual traction. It is often performed via an incomplete osteotomy or corticotomy and is fixed with an external device. After 5 days of latency, the device is activated at a rate of $1 \mathrm{~mm}$ daily (four times of unscrewing per day, each time for $0.25 \mathrm{~mm}$ ). Next, the consolidation phase starts with the presence of the device at the site to achieve optimal bone strength. ${ }^{25}$

Evidence shows that many pro-inflammatory factors such as bone morphogenetic proteins, interleukins 1, 2, 4 and 6 and RANKL/OPG play a role in different phases of $\mathrm{DO}$, including the consolidation, active distraction and latency phases. ${ }^{26}$ It has been proposed that viable tissue under mild but uniform tension induces the mechanotransduction mechanism and stimulates the cell function. ${ }^{24}$ Also, evidence shows that new bone (both cancellous and cortical) starts to form radially within 14 days following the initiation of the distraction phase. ${ }^{27}$ DO is performed in patients with craniofacial syndromes and disorders, especially children with such conditions by using intra-oral devices..$^{28-30} \mathrm{DO}$ of the mandible has shown successful results for the resolution of upper airway obstruction in children. ${ }^{31}$ The advantages of DO include (I) greater bone movement, (II) not requiring bone grafting, (III) concomitant soft tissue adaptation, (IV) suitability for growing and non-growing individuals, (V) shorter surgical time, and (VI) the ability for more extensive applications. ${ }^{32}$

Adult patients with significant horizontal problems of the base of the maxilla are good candidates for surgicallyassisted rapid palatal expansion (SARPE), ${ }^{33}$ which is a type of DO and indirectly expands the maxilla. ${ }^{34} \mathrm{DO}$ of the zygoma and skull is also feasible. DO can be combined with other routine surgical procedures of the jaws as well. ${ }^{35}$

To the best of the present authors' knowledge, no review study is available on the effects of PBM on DO. Thus, this study aimed to review the published articles on the effects

\section{of PBM or LLLT on DO.}

\section{Materials and Methods}

An electronic search of the literature was carried out in Google Scholar, PubMed and Science Direct for English articles with no time limitation, which yielded 21 articles in Google Scholar, 24 articles in PubMed and 38 articles in Science Direct using the keywords "low-level laser therapy AND Distraction Osteogenesis OR surgically assisted rapid palatal expansion". After reading the titles and abstracts, 18 articles were chosen for the evaluation of their full texts. Table 1 summarizes the findings of these 18 articles based on their publication year, title, study design (clinical or experimental), laser type, laser properties, DO protocol, method of bone assessment and final conclusion.

\section{Results}

Eighteen articles met the inclusion criteria. These articles evaluated the effect of PBM or LLLT with different types of lasers, wavelengths, power and irradiation protocols on DO and SARPE in different phases of DO. A total of 15 animal studies and 3 human studies were evaluated. Of 3 human studies, 2 studies assessed the effect of LLLT on $\mathrm{DO}$ and the remaining one assessed the effect of LLLT on SARPE.

Only one study evaluated the effect of the Ga-As laser with a $970 \mathrm{~nm}$ wavelength on DO. ${ }^{36}$ Only one study assessed the effect of the Ga-As laser with a $905 \mathrm{~nm}$ wavelength on DO. ${ }^{37}$ Twelve studies assessed the effect of the Ga-Al-As laser with 808 to $830 \mathrm{~nm}$ wavelengths on DO in different areas of the maxillofacial region.

Three studies did not mention the type of the laser and one study only mentioned the commercial brand-name of the laser device. ${ }^{38}$

\section{Discussion}

Santinoni et al, in 2017, evaluated the efficacy of LLLT in the healing of maxillofacial bone defects. ${ }^{54}$ They only reviewed randomized clinical trials in their systematic review. Studies on transverse maxillary expansion and maxillary cystic defects, one study on DO of the mandible, ${ }^{37}$ and studies on cases after tooth-extraction, orthodontic tooth movement and periodontal defects were reviewed. According to their results, PBM can probably enhance the healing of post-surgical defects in the maxillofacial region. The current study reviewed the effects of $\mathrm{PBM}$ on DO. Both animal and human studies were reviewed in our study. Another difference between our study and that of Santinoni et al was that we reviewed the applications of PBM not only to the healing phase of defects, but also to the latency and activation phases. Our findings were close to those of Santinoni et al, and the majority of reviewed studies pointed to the stimulatory effect of LLLT on bone healing. Since histological assessment of viable human tissues is not possible in clinical studies, none of the studies 


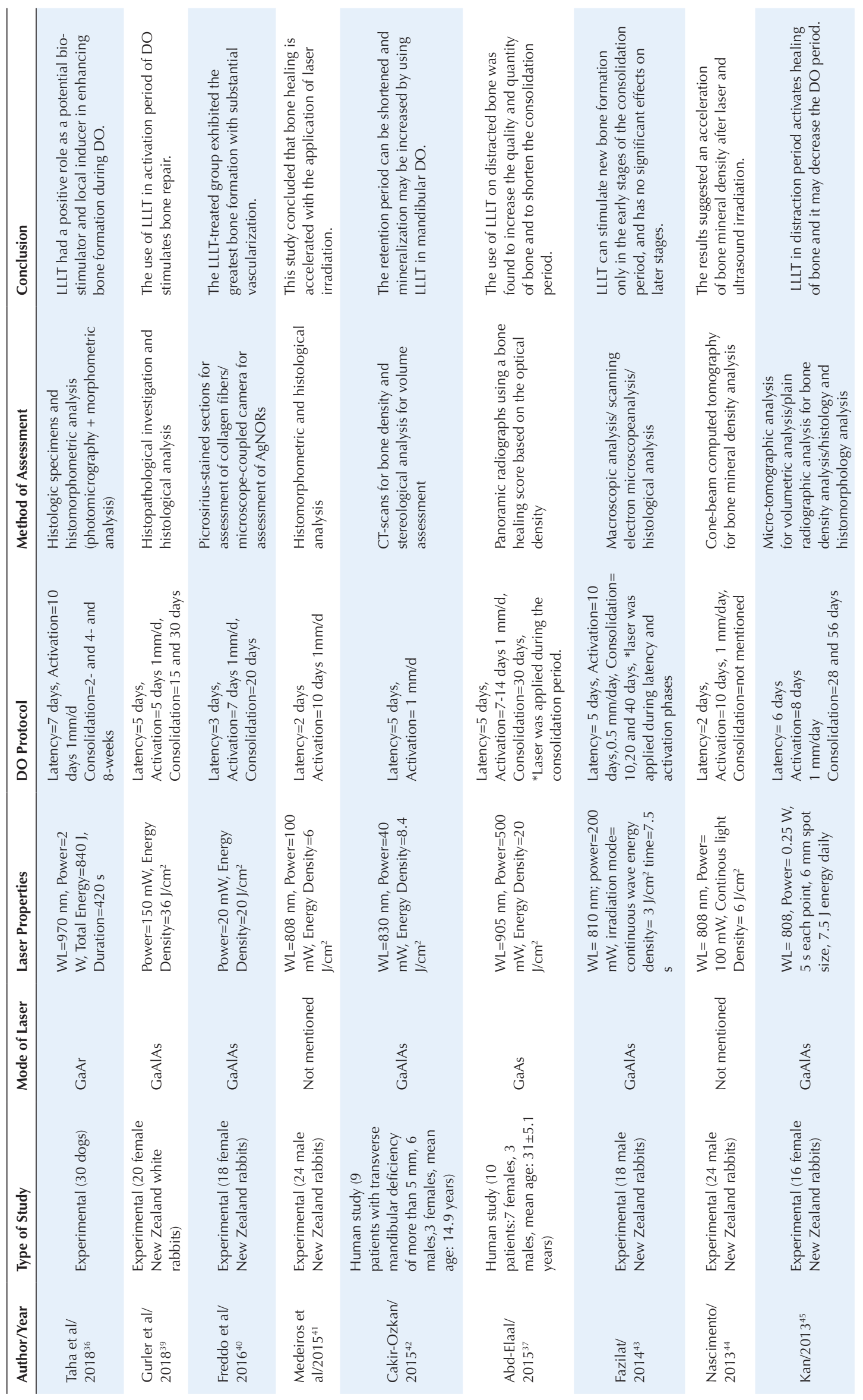




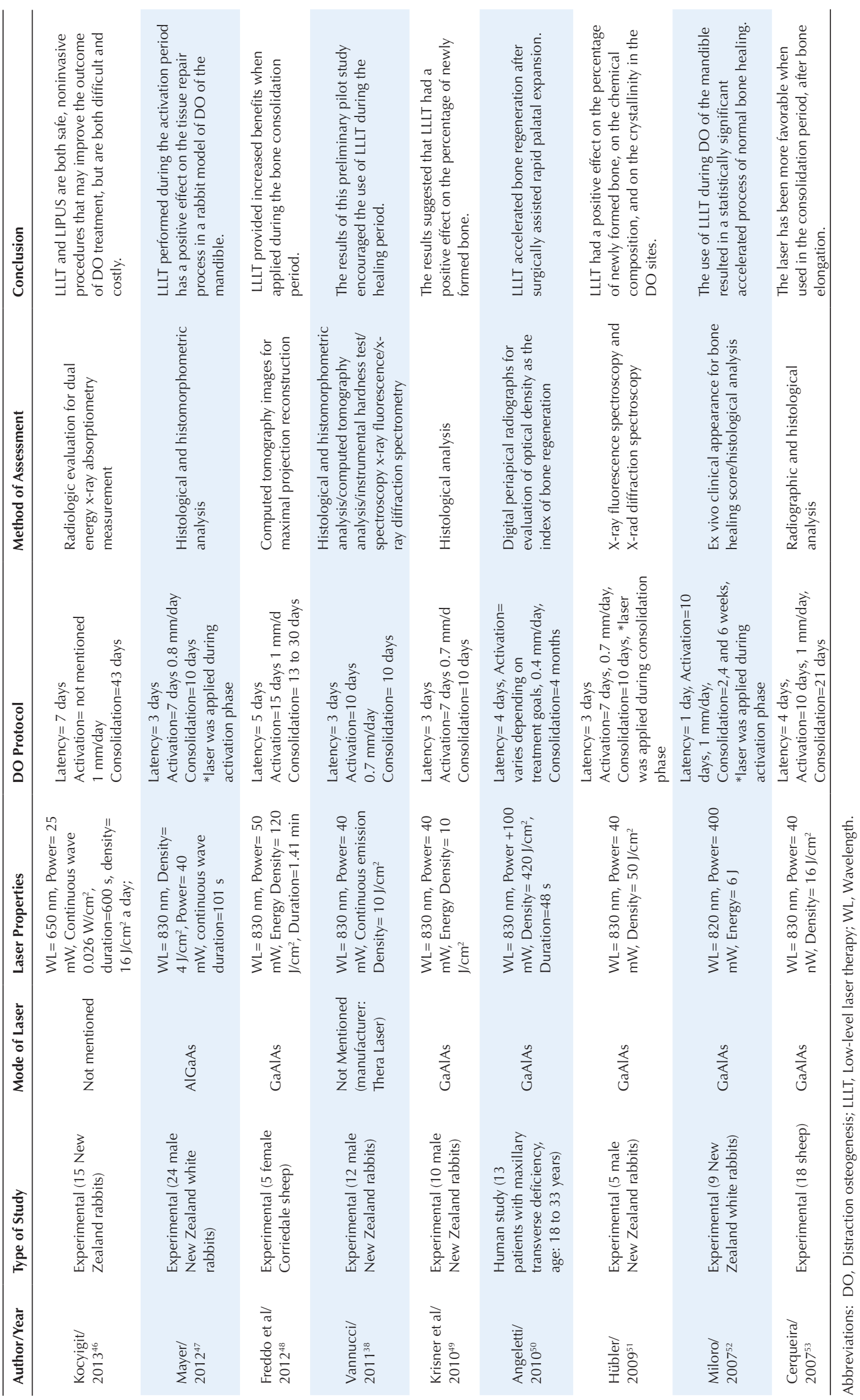


reviewed by Santinoni et al performed a histological analysis of bone. In the present review, however, animal studies were also included, which histologically analyzed bone. Similar to the study by Santinoni et al, we did not have a uniform specific irradiation protocol for LLL in our reviewed studies.

Ebrahimi et al, in 2012, evaluated the effect of LLLT on bone healing. ${ }^{55}$ Their study mainly focused on histological aspects and evaluated the effect of LLL mainly on osteoblasts. They did not limit their review to animal or human studies only. The majority of reviewed studies had an in vitro design or had been conducted in vivo on an animal model. They concluded that LLLT can accelerate the rate of bone healing in the extraction sockets, sites of bone fracture and DO in animal models. Our study, similar to that of Ebrahimi et al, did not limit the review to animal or human studies only. Our findings were in agreement with theirs and confirmed the positive effect of PBM on the healing of DO defects.

Noba et al, in 2017, evaluated the effect of lasers on bone healing after oral surgery. ${ }^{7}$ They concluded that $\mathrm{PBM}$ accelerates bone healing but there is no standard protocol for its use following surgical procedures. However, evidence in this respect is still inconclusive. The current study, similar to that of Noba et al, assessed both human and animal studies. The reviewed studies did not follow the same protocol of DO. This was also the case in the study by Noba et al. Our findings were in line with those of Noba et al.

Davoudi et al, in 2018, evaluated the articles on the effects of laser therapy on patients under rapid maxillary expansion (RME). ${ }^{56}$ They reviewed randomized clinical trials, which had performed RME with/without surgery. They reviewed four articles. Only one study evaluated the effect of laser irradiation on SARPE. They showed that LLL can be used in the primary phases of maxillary expansion because it increases the speed of bone remodeling. Since SARPE follows the principles of DO, we also reviewed a study on the effect of PBM on SARPE. ${ }^{50}$ The results of that study were somehow in line with those of Davoudi et al, but contrary to the findings of Davoudi et al, the results from that study showed that lasers should be used not only in the primary and active phases of DO, but also in the consolidation phase.

Moreover, the current study reviewed seven articles on the effects of LLLT on the consolidation phase of DO. ${ }^{36-}$ $38,40,46,49,51$ Six studies evaluated the effect of LLLT on the activation phase of $\mathrm{DO}^{39,41,44,45,47,52}$ and three studies evaluated the effect of LLLT on the latency and activation phases of DO. ${ }^{42,43,50}$ However, Angeletti et $\mathrm{al}^{50}$ did not accurately mention these two phases but the timing of laser irradiation was within these two phases. In a study by Freddo et al, one group was subjected to laser irradiation in the latency and activation phases and the other group in the consolidation phase. ${ }^{48}$ Cerqueira et al performed laser therapy in the activation phase in one group and in the consolidation phase in another group..$^{53}$ It appears that no consensus exists regarding the most suitable phase of DO for laser irradiation.

The reviewed studies had some differences regarding the location of corticotomy incisions in DO. Studies on the mandible of rabbits also had different locations of incision, including distal to the mental foramen and distal to the first molar, ${ }^{39}$ between the first premolar and mental foramen, ${ }^{48}$ at $1 \mathrm{~mm}$ distance from the mesial root of the first molar, ${ }^{41,44}$ in the medial and lateral cortices right in front of the first premolar, ${ }^{43}$ anterior to the molar teeth and posterior to the mental foramen, ${ }^{45} 1 \mathrm{~cm}$ mesial to the ramus, ${ }^{46}$ between the premolar site and mental foramen, ${ }^{38,47}$ and body of mandible right behind the mental foramen. ${ }^{52}$ Two studies on the mandible of rabbits did not mention the exact location of the incision and they only discussed that an incision was made in such a way that the inferior alveolar nerve was not traumatized. ${ }^{49,51}$ One study was conducted on dogs with an incision line between the mandibular second and third premolars. Two studies evaluated sheep: one of them reported an incision line in the internal and external surface of the gonial angle $e^{40}$ and the other one reported an incision made in the body of mandible right behind the mental foramen. ${ }^{53}$

The incision lines in the 3 reviewed human studies were as follows: It was on the mandible in two studies; one had an incision at the midline of the mandible ${ }^{42}$ and the other one had an incision in the body of mandible right in front of the gonial angle. ${ }^{37}$ Another study reported that the incision line was on the maxilla under LeFort I surgery and all sutures including the pterygomaxillary suture were opened..$^{50}$ No agreement existed among the studies regarding the incision line for $\mathrm{DO}$ of the mandible. Studies on animal models used different incision lines.

No consensus existed among the studies regarding the laser protocol or the irradiated site. One study reported intraoral laser irradiation 5 times a day, perpendicular to the buccal surface for 2 minutes and crest area for 3 minutes in the consolidation phase. They also performed extraoral laser irradiation of the inferior border of the mandible for 2 minutes with $320 \mathrm{~mm}$ spot size. ${ }^{36}$ Another study irradiated three points measuring $1 \mathrm{~cm}^{2}$ in size in the buccal and 3 points in the lingual for 40 seconds. ${ }^{39}$ Another study reported laser irradiation on the first day of the maturation phase and then for another 9 sessions every 48 hours (a total of 10 sessions). The irradiated sites included 4 points around the DO area for 10 seconds. ${ }^{40}$ Two studies performed laser therapy every night for 6 minutes for a total of 24 times. They did not report the exact location of irradiated sites. ${ }^{41,44}$ Another study irradiated the laser to 2 areas at the mandibular midline. The first area was the alveolar bone between the roots of central incisors and the second area was at the buccal sulcus depth at the midline $5 \mathrm{~mm}$ beneath the first irradiated area. In each session, 2 laser doses were administered (one dose for each area). 
The first irradiation was performed during the first 24 hours postoperatively and the remaining irradiation was performed every 48 hours. In total, each patient underwent 8 sessions of laser therapy. ${ }^{42}$ Another study reported laser irradiation in the consolidation phase at 4 points of the osteotomy site including two lateral points and 2 points in the inferior region of the body of the mandible. Laser therapy was performed for 12 sessions, each session for 2 minutes. ${ }^{37}$ Another study performed the first laser irradiation perpendicular to the surgical site from the medial and lateral aspects in two points after surgery. The diameter of the laser irradiated site was 0.8 $\mathrm{mm}$ and the irradiation time was 7.5 seconds. Irradiation was performed once a day for 14 days. ${ }^{43}$ Another study irradiated three points in the buccal and three points in the lingual (sites of DO), measuring $6 \mathrm{~mm}$ in size for 5 seconds for 6 days. ${ }^{45}$ Another study irradiated laser to a point measuring $0.95 \mathrm{~cm}^{2}$ in size twice a day, each time for 300 seconds for a total of 10 days. They did not mention the exact location of the irradiated site. ${ }^{46}$ In another study, the laser was directly irradiated to the site of DO in three points along the osteotomy line for 1.41 minutes immediately after surgery and every 48 hours. The total number of irradiation sessions was eight. ${ }^{40}$ Another study reported laser irradiation in the consolidation phase every 48 hours until the end of this phase. They did not report the exact location of the irradiated site. ${ }^{49}$ Another study reported laser irradiation of three points at the DO site perpendicular to this location for a total of 1.41 seconds after the activation of the device once every 48 hours. The total number of sessions was four. ${ }^{47}$ Another study reported direct irradiation of DO site in the consolidation phase every 48 hours. ${ }^{38}$

In another study, 3 points in the palate measuring $0.06 \mathrm{~cm}^{2}$ were irradiated (I) the first point was at the incisive papilla, (II) the second point was at the line connecting the two lateral incisors $2 \mathrm{~mm}$ right to the mid-palatal raphe, and (III) the third point was at the line connecting the two lateral incisors $2 \mathrm{~mm}$ left to the mid-palatal raphe. One dose of the laser was irradiated in each session and each patient underwent a total of 8 sessions of laser therapy. The first laser therapy session was held 24 hours after surgery for 84 seconds each time and laser irradiation was then repeated every 48 hours. The researchers reported that the laser tip was at close contact with the irradiation site. ${ }^{50}$

Another study reported laser irradiation every 48 hours in the consolidation phase for 10 days. They did not specify the exact location of irradiation. ${ }^{51}$ Another study irradiated six points on the buccal and lingual surfaces (sites of DO) for 10 days. ${ }^{52}$ Another study reported direct daily irradiation of the site of DO with the laser through the skin at 4 points along the corticotomy line..$^{53}$

Considering the results of the reviewed studies, the positive effect of PBM on DO site is obvious. However, a standard protocol for laser irradiation does not exist and there is no consensus among the published studies regarding the phase of DO most suitable for PBM.

\section{Ethical Considerations}

Not applicable.

\section{Conflict of Interests}

The authors declare no conflict of interest.

\section{References}

1. Sousa MV, Pinzan A, Consolaro A, Henriques JF, de Freitas MR. Systematic literature review: influence of lowlevel laser on orthodontic movement and pain control in humans. Photomed Laser Surg. 2014;32(11):592-9. doi:10.1089/pho.2014.3789

2. Eells J, Henry M, Summerfelt P, Wong-Riley M, Buchmann E, Kane M, et al. Therapeutic photobiomodulation for methanol-induced retinal toxicity. Proc Nati Acad of Sci US A. 2003;100(6):3439-44. doi.org/10.1073/pnas.0534746100

3. Oron U, Ilic S, De Taboada L, Streeter J. Ga-As (808 $\mathrm{nm}$ ) laser irradiation enhances ATP production in human neuronal cells in culture. Photomed Laser Surg. 2007;25(3):180-2. doi.org/10.1089/pho.2007.2064

4. Leonida A, Paiusco A, Rossi G, Carini F, Baldoni M, Caccianiga G. Effects of low-level laser irradiation on proliferation and osteoblastic differentiation of human mesenchymal stem cells seeded on a threedimensional biomatrix: in vitro pilot study. Lasers Med Sci. 2013;28(1):125-32. doi:10.1007/s10103-012-1067-6

5. Pires Oliveira DA, de Oliveira RF, Zangaro RA, Soares CP. Evaluation of low-level laser therapy of osteoblastic cells. Photomed Laser Surg. 2008;26(4):401-4. doi:10.1089/ pho.2007.2101

6. Fujita $S$, Yamaguchi $M$, Utsunomiya $T$, Yamamoto $H$, Kasai K. Low-energy laser stimulates tooth movement velocity via expression of RANK and RANKL. Orthod Craniofac Res. 2008;11(3):143-55. doi:10.1111/j.16016343.2008.00423.x

7. Noba C, Mello-Moura ACV, Gimenez T, Tedesco TK, Moura-Netto C. Laser for bone healing after oral surgery: systematic review. Lasers Med Sci. 2018;33(3):667-74. doi. org/10.1007/s10103-017-2400-x

8. Silva Júnior AN, Pinheiro AL, Oliveira MG, Weismann R, Pedreira Ramalho LM, Amadei Nicolau R. Computerized morphometric assessment of the effect of low-level laser therapy on bone repair: an experimental animal study. J Clin Laser Med Surg. 2002;20(2):83-7. doi:10.1089/104454702753768061

9. Rahimi A, Rabiei S, Mojahedi SM, Kosarieh E. Application of low level laser in temporomandibular disorders. J Lasers Med Sci. 2011;2(4):165-70.

10. Seyyedi SA, Olyaee P, Sani ZD, Falaki F. Low level laser therapy (LLLT) for orofacial pain. J Lasers Med Sci. 2012;3(3):97-101.

11. Carroll JD, Milward MR, Cooper PR, Hadis M, Palin WM. Developments in low level light therapy (LLLT) for dentistry. Dent Mater. 2014;30(5):465-75. doi:10.1016/j. dental.2014.02.006

12. Khadra M, Kasem N, Haanæs HR, Ellingsen JE, Lyngstadaas 
SP. Enhancement of bone formation in rat calvarial bone defects using low-level laser therapy. Oral Surg Oral Med Oral Pathol Oral Radiol Endod. 2004;97(6):693-700. doi:10.1016/j.tripleo.2003.11.008

13. Pretel H, Lizarelli RF, Ramalho LT. Effect of low-level laser therapy on bone repair: Histological study in rats. Lasers Surg Med. 2007;39(10):788-96. doi:10.1002/lsm.20585

14. PuglieseLS,MedradoAP,ReisSR,AndradeZD.Theinfluence of low-level laser therapy on biomodulation of collagen and elastic fibers. Pesqui Odontol Bras. 2003;17(4):307-13. doi:10.1590/S1517-74912003000400003

15. Mirsky N, Krispel Y, Shoshany Y, Maltz L, Oron U. Promotion of angiogenesis by low energy laser irradiation. Antioxid Redox Signal. 2002;4(5):785-90. doi:10.1089/152308602760598936

16. Mok Y, Pang K, Au C, Yew D. Preliminary observations on the effects in vivo and in vitro of low dose laser on the epithelia of the bladder, trachea and tongue of the mouse. Scanning Microsc. 1988;2(1):493-502.

17. Vinck EM, Cagnie BJ, Cornelissen MJ, Declercq HA, Cambier DC. Increased fibroblast proliferation induced by light emitting diode and low power laser irradiation. Lasers Med Sci. 2003;18(2):95-9. doi:10.1007/s10103-003-0262-x

18. Farivar S, Malekshahabi T, Shiari R. Biological effects of low level laser therapy. J Lasers Med Sci. 2014;5(2):58. doi. org/10.22037/jlms.v5i2.5540

19. Lim H-M, Lew KK, Tay DK. A clinical investigation of the efficacy of low level laser therapy in reducing orthodontic postadjustment pain. Am J of Orthod and Dentofacial Orthop. 1995;108(6):614-22. doi:10.1016/S08895406(95)70007-2

20. Dörtbudak O, Haas R, Mailath-Pokorny G. Biostimulation of bone marrow cells with a diode soft laser. Clin Oral Implants Res. 2000;11(6):540-5. doi:10.1034/j.16000501.2000.011006540.x

21. Kasai S, Kono T, Yamamoto Y, Kotani H, Sakamoto T, Mito M. Effect of low-power laser irradiation on impulse conduction in anesthetized rabbits. J Clin Laser Med Sur. 1996;14(3):107-9. doi:10.1089/clm.1996.14.107

22. Marquezan M, Bolognese AM, de Souza Araújo MT. Effects of two low-intensity laser therapy protocols on experimental tooth movement. Photomed Laser Surg. 2010;28(6):757-62. doi:10.1089/pho.2009.2694

23. Ozawa Y, Shimizu N, Kariya G, Abiko Y. Low-energy laser irradiation stimulates bone nodule formation at early stages of cell culture in rat calvarial cells. Bone. 1998;22(4):347-54. doi:10.1016/S8756-3282(97)00294-9

24. Ilizarov GA. The tension-stress effect on the genesis and growth of tissues. Part I. The influence of stability of fixation and soft-tissue preservation. Clin Orthop Relat Res. 1989(238):249-81.

25. Aronson J. Experimental and clinical experience with distraction osteogenesis. Cleft Palate Craniofac J. 1994;31(6):473-82. doi:10.1597/1545-1569_1994_031_0473_ eacewd_2.3.co_2

26. Ai-Aql Z, Alagl AS, Graves DT, Gerstenfeld LC, Einhorn TA. Molecular mechanisms controlling bone formation during fracture healing and distraction osteogenesis. J Den Res. 2008;87(2):107-18. doi:10.1177/154405910808700215

27. Aronson J, Good B, Stewart C, Harrison B, Harp J.
Preliminary studies of mineralization during distraction osteogenesis. Clin Orthop Relat Res. 1990(250):43-9.

28. Tahiri Y, Taylor J, editors. An update on midface advancement using Le Fort II and III distraction osteogenesis. Semin Plast Surg. 2014; 28(4):184-192. doi:10.1055/s-0034-1390171

29. Dimitroulis G. Condylar injuries in growing patients. Aust Dent J. 1997;42(6):367-71. doi:10.1111/j.1834-7819.1997. tb06079.x

30. Chin M, Toth BA. Distraction osteogenesis in maxillofacial surgery using internal devices: review of five cases. J Oral Maxillofac Surg. 1996;54(1):45-53. doi:10.1016/S02782391(96)90303-1

31. Cohen SR, Simms C, Burstein FD. Mandibular distraction osteogenesis in the treatment of upper airway obstruction in children with craniofacial deformities. Plast Reconstr Surg. 1998;101(2):312-8. doi:10.1097/00006534-19980200000008

32. Barber S, Carter L, Mannion C, Bates C. Distraction Osteogenesis Part 1: History and Uses in the Craniofacial Region. Orthod Update. 2018;11(1):14-20. doi:10.12968/ ortu.2018.11.1.14

33. Koudstaal M, Poort L, Van der Wal K, Wolvius E, PrahlAndersen B, Schulten A. Surgically assisted rapid maxillary expansion (SARME): a review of the literature. Int $J$ Oral Maxillofac Surg. 2005;34(7):709-14. doi:10.1016/j. ijom.2005.04.025

34. Starch-Jensen T, Blæhr TL. Transverse expansion and stability after segmental Le fort I osteotomy versus surgically assisted rapid maxillary expansion: a systematic review. J Oral Maxillofac Res. 2016;7(4): e1. doi: 10.5037/ jomr.2016.7401.

35. McCarthy JG, Stelnicki EJ, Mehrara BJ, Longaker MT. Distraction osteogenesis of the craniofacial skeleton. Plast ReconstrSurg. 2001;107(7):1812-27. doi:10.1097/00006534200106000-00029

36. Taha SK, El Fattah SA, Said E, Abdel-Hamid M, Nemat AH, El Shenawy H. Effect of laser bio-stimulation on mandibular distraction osteogenesis: an experimental study. J Oral Maxillofac Surg. 2018;76(11):2411-2421. doi: 10.1016/j.joms.2018.04.030.

37. Abd-Elaal AZ, El-Mekawii HA, Saafan AM, El Gawad LA, El-Hawary YM, Abdelrazik MA. Evaluation of the effect of low-level diode laser therapy applied during the bone consolidation period following mandibular distraction osteogenesis in the human. Int J Oral Maxillofac Surg. 2015;44(8):989-97. doi: 10.1016/j.ijom.2015.04.010.

38. Vannucci MG, Dreyer J, Kreisner P, Gaião L, Moraes JFD, de Oliveira MG. Histological and physical analysis of bone neoformation by osteogenesis distraction: A preliminary report. Ann Maxillofac Surg. 2011;1(1):26-31. doi:10.4103/2231-0746.83150

39. Gurler G, Gursoy B. Investigation of effects of low level laser therapy in distraction osteogenesis. J Stomatol Oral Maxillofac Surg. 2018;119(6):469-76. doi:10.1016/j. jormas.2018.05.006

40. Freddo AL, Giongo CC, Ponzoni D, Corsetti A, Puricelli E. Influence of a Magnetic Field and Laser Therapy on the Quality of Mandibular Bone During Distraction Osteogenesis in Rabbits. JOral Maxillofac Surg. 2016;74(11): 
2287.e1-e8. doi:10.1016/j.joms.2016.07.010

41. Medeiros MA, do Nascimento LE, Lau TCL, Mineiro AL, Pithon MM, Sant'Anna EF. Effects of laser vs ultrasound on bone healing after distraction osteogenesis: A histomorphometric analysis. Angle Orthod. 2014;85(4):55561. doi.org/10.2319/061414-431.1

42. Cakir-Ozkan N, Bereket C, Arici N, Elmali M, Sener I, Bekar E. The radiological and stereological analysis of the effect of low-level laser therapy on the mandibular midline distraction osteogenesis. J Craniofac Surg. 2015;26(7): e595-9. doi: 10.1097/SCS.0000000000002046.

43. Fazilat F, Ghoreishian M, Fekrazad R, Kalhori KA, Khalili SD, Pinheiro ALB. Cellular effect of low-level laser therapy on the rate and quality of bone formation in mandibular distraction osteogenesis. Photomed Laser Surg. 2014;32(6):315-21. doi:10.1089/pho.2013.3559

44. do Nascimento LEAG, Sant'Anna EF, de Oliveira Ruellas AC, Nojima LI, Gonçalves Filho AC, Freitas SAP. Laser versus ultrasound on bone density recuperation after distraction osteogenesis- A cone-beam computer tomographic analysis. J Oral Maxillofac Surg. 2013;71(5):921-8. doi:10.1016/j.joms.2012.11.010

45. Kan B, Tasar F, Korkusuz P, Ersoy O, Cetinkaya A, Gur CZ, et al. Histomorphometrical and radiological comparison of low-level laser therapy effects on distraction osteogenesis: experimental study. Lasers Med Sci. 2014;29(1):213-20. doi:10.1007/s10103-013-1308-3

46. Kocyigit ID, Coskunses FM, Pala E, Tugcu F, Onder E, Mocan A. A comparison of the low-level laser versus low intensity pulsed ultrasound on new bone formed through distraction osteogenesis. Photomed Laser Surg. 2012;30(8):438-43. doi:10.1089/pho.2012.3263

47. Mayer L, Freddo AL, Blaya DS, de Oliveira MG, De Conto F. Effects of low-level laser therapy on distraction osteogenesis: a histological analysis. RFO UPF. 2012;17(3):326-31.

48. Freddo A-L, Hübler R, de Castro-Beck C-A, Heitz C, de Oliveira M-G. A preliminary study of hardness and modulus of elasticity in sheep mandibles submitted to distraction osteogenesis and low-level laser therapy. Med
Oral Patol Oral Cir Bucal. 2012;17(1): e102-e107. 10.4317/ medoral.17280

49. Kreisner PE, Blaya DS, Gaião L, Santos MESM, Etges A, Sant'Ana Filho M, et al. Histological evaluation of the effect of low-level laser on distraction osteogenesis in rabbit mandibles. Med oral Patol Oral Cir Bucal. 2010;15(4): e616-e618. doi:10.4317/medoral.15.e616

50. Angeletti P, Pereira MD, Gomes HC, Hino CT, Ferreira LM. Effect of low-level laser therapy (GaAlAs) on bone regeneration in midpalatal anterior suture after surgically assisted rapid maxillary expansion. Oral Surg Oral Med Oral Pathol Oral Radiol Endod. 2010;109(3): e38-e46. doi:10.1016/j.tripleo.2009.10.043

51. Hübler R, Blando E, Gaião L, Kreisner PE, Post LK, Xavier CB, et al. Effects of low-level laser therapy on bone formed after distraction osteogenesis. Lasers Med Sci. 2010;25(2):213-9. doi:10.1007/s10103-009-0691-2

52. Miloro M, Miller JJ, Stoner JA. Low-level laser effect on mandibular distraction osteogenesis. J Oral Maxillofac Surg. 2007;65(2):168-76. doi:10.1016/j.joms.2006.10.002

53. Cerqueira A, Silveira RL, Oliveira MGd, Sant'ana Filho M, Heitz C. Bone tissue microscopic findings related to the use of diode laser (830etam) in ovine mandible submitted to distraction osteogenesis. Acta Cir Bras. 2007;22(2):92-7. doi.org/10.1590/S0102-86502007000200003

54. Santinoni CD, Oliveira HF, Batista VE, Lemos CA, Verri FR. Influence of low-level laser therapy on the healing of human bone maxillofacial defects: A systematic review. J Photochem Photobiol B. 2017;169:83-9. doi:10.1016/j. jphotobiol.2017.03.004

55. Ebrahimi T, Moslemi N, Rokn A, Heidari M, Nokhbatolfoghahaie H, Fekrazad R. The influence of lowintensity laser therapy on bone healing. J Dent (Tehran). 2012;9(4): 238-248.

56. Davoudi A, Amrolahi M, Khaki H. Effects of laser therapy on patients who underwent rapid maxillary expansion; a systematic review. Lasers Med Sci. 2018; 33(6): 1387-1395. doi:10.1007/s10103-018-2545-2 